\title{
AS BRINCADEIRAS E AS LINGUAGENS NA EDUCAÇÃO INFANTIL
}

\author{
Cristiane Catarina de Oliveira Passos ${ }^{1}$ \\ Elenice Patricio Bezerra² \\ Jacques Lenoir Gusmão Moraes ${ }^{3}$ \\ Meire Lucinda Correa ${ }^{4}$ \\ Uetes do Carmo Santos ${ }^{5}$ \\ Wanderson Rodrigues Miranda ${ }^{6}$
}

RESUMO: As brincadeiras são práticas essenciais para o desenvolvimento da criança, como uma forma lúdica de aprender na Educação Infantil. Os especialistas mudaram as suas concepções sobre as brincadeiras, a partir da identificação dos seus diversos benefícios no desenvolvimento global da criança, nos componentes motor e intelectual. O objetivo geral deste estudo é discutir a importância das brincadeiras na educação infantil, como instrumento facilitador do processo de desenvolvimento das linguagens, com a utilização da ludicidade. $O$ método de pesquisa emprego foi a pesquisa bibliográfica. Assim, esse estudo se justifica pelo fato de a infância representar um conjunto de possibilidades, pois o indivíduo possui a necessidade de se expressar e de adquirir conhecimentos. As brincadeiras são estratégias que facilitam o desenvolvimento das linguagens no desenvolvimento global das crianças da educação infantil.

Palavras-chave: Brincadeiras. Educação Infantil. Atividades Lúdicas. Desenvolvimento Global das Crianças. As Linguagens das Crianças.

\footnotetext{
I Pós Graduação em: Educação das Relações Étnicos Raciais no Contexto da Educação de Jovens e Adultos. Pela Universidade Federal de Mato Grosso- UFMT - 2or6.E mail:Email:cristiane94.passos@gmail.com

2 Graduada em Licenciatura em Pedagogia pela Universidade de Cuiabá-UNIC. Pós-graduada em Educação Especial e Inclusão pelas Faculdades Integradas de Várzea Grande-FIVE. Pós-graduada em Educação Infantil e Alfabetização pelas Faculdades Integradas de Várzea

Grande-FIVE.E-mail: patricior6.giovana@gmail.com

3 Graduação em licenciatura plena de Educação Física pela Universidade Federal de Mato Grosso. Pós graduação em Educação, motricidade e recreação - ICE - instituto Cuiabano de Educação. Email: jacqueslgusmao@yahoo.com.br

4 Graduação: universidade luterana do brasil. licenciatura em pedagogia. Pós graduação: faculdade de tecnologia equipe darwin. curso de pós- graduação latu sensu em educação infantil na primeira infância e anos iniciais. pós graduação: centro universitário leonardo da vinci curso: psicopedagogia.

5 Pós-graduado em Educação Infantil e Ensino Fundamental ( UNIP-DF) Pós graduado em Docência do Ensino Superior pela Faculdade de Ciências de Wenceslau Braz (Facibra). Licenciado em Educação Física Universidade Paulista (UNIP). E-mail: pefprofessor@gmail.com

6 Graduado em Licenciatura em Computação pelo Instituto Federal de Educação, Ciência e Tecnologia do Tocantins; Graduado em Licenciatura em Educação Física pela Universidade Norte do Paraná; Graduado em Licenciatura em Pedagogia pelas Faculdades Integradas de Itararé - FAFIT; Pós-graduando em Educação Infantil e Ensino Fundamental pela Faculdade FAMART; E-mail: miranda.wanderson@gmail.com.
} 
ABSTRACT: The games are essential practices for the child's development, as a playful way of learning in Kindergarten. The specialists changed their conceptions about games, based on the identification of their various benefits in the child's global development, in terms of motor and intellectual components. The general objective of this study is to discuss the importance of games in early childhood education, as an instrument to facilitate the process of language development, with the use of playfulness. The job search method was bibliographic research. Thus, this study is justified by the fact that childhood represents a set of possibilities, as the individual has the need to express themselves and acquire knowledge. The games are strategies that facilitate the development of languages in the global development of children in kindergarten.

Keywords: Jokes. Child education. Playful Activities. Children's Global Development. Children's Languages.

\section{INTRODUÇÃO}

As brincadeiras são práticas essenciais para o desenvolvimento da criança, como uma forma lúdica de aprender na Educação Infantil. A cada momento, no brincar, as crianças desempenham atos e papéis diferenciados e que em sua intencionalidade e curiosidade resultam num processo criativo para modificar, imaginariamente, a realidade e o presente. As brincadeiras podem ser realizadas em suas diversas formas, produzindo significados e promovendo ressignificados.

Os especialistas mudaram as suas concepções sobre as brincadeiras, a partir da identificação dos diversos benefícios delas no desenvolvimento da criança, nos componentes motor e intelectual. Assim, levantou-se a seguinte problemática: Como o professor pode trabalhar as potencialidades das brincadeiras para $o$ desenvolvimento da linguagem nos alunos a educação infantil?

O objetivo geral deste estudo é discutir a importância das brincadeiras na educação infantil, como instrumento facilitador do processo de desenvolvimento das linguagens, com a utilização da ludicidade. Os objetivos específicos para o desenvolvimento deste estudo são os seguintes: contextualizar a educação infantil; abordar sobre a ludicidade; e refletir sobre as potencilidades das brincadeiras no desenvolvimento das linguagens na educação infantil.

Assim, esse estudo se justifica pelo fato da infância representar um conjunto de possibilidades, pois o indivíduo possui a necessidade de se expressar e de adquirir 
conhecimentos. $\mathrm{Na}$ criança, essas necessidades são manifestadas nas brincadeiras, que não se tratam somente de diversão, mas uma forma de linguagem. Dessa forma esse tema é fundamental tanto para os alunos, quanto para professores e acadêmicos, pois contribui para a formação de atitudes como respeito, cooperação, relação social, interação, ou seja, constituindo bases para auxiliar a construção do conhecimento.

O método de pesquisa emprego foi a pesquisa bibliográfica, utilizando-se livros, artigos científicos, monografias, dissertações de Mestrado e teses de Doutorado. No desenvolvimento da pesquisa, foi fomentada por abordagens de publicações de especialistas, encontradas nas bases Scielo, Redalyc e de diversas universidades.

Assim, buscou-se uma discussão e uma reflexão sobre as potencialidades das brincadeiras no desenvolvimento das linguagens na educação infantil, comparando teorias de grandes estudiosos. A contextualização da criança na educação infantil passa pelas abordagens dos autores Alves (20II), Campos et al (20II), Paschoal e Machado (2009). A abordagem da ludicidade que envolve o desenvolvimento da criança compreende a dialética entre os autores Dias (2013), Lopes (2016), Niles e Sosha (2014). A reflexão sobre as potencialidades das brincadeiras no desenvolvimento das linguagens na educação infantil se desenvolve embasada nas definições de Bueno (2010), Kishimoto (2010) e Barbosa, Martins e Mello (2017) e Silva (2020).

\section{EDUCAÇÃO INFANTIL}

A educação infantil é componente da educação básica, onde se trabalha o desenvolvimento inicial escolar das crianças, que se enquadram na faixa etária que antecede aos 7 anos de idade. Pardal (2005) aborda que as primeiras ideias da concepção de creche no país se desenvolveram a partir da participação do imperador Dom Pedro II e da Imperatriz na vigésima sessão pública da Sociedade das Creches em Paris, definindo uma versão brasileira das creches com fundamentação em uma sociedade beneficente que desejam concorrer e fundar uma instituição para crianças pobres de menos de dois anos, de mães que trabalham fora dos seus domicílios e 
possuem uma boa conduta. Silva e Francischini (2012) observam que as creches surgem por meio de uma divisão de classes, ao se propor atender somente as crianças pobres.

Campos et al (20II) observam uma evolução na educação infantil nas últimas décadas, em decorrência da ampliação do acesso destas crianças às creches e préescolas. Os referidos autores compreendem que essa condição foi influenciada pelos seguintes processos sociais: urbanização, crescimento econômico, lutas sociais, mudança do papel da mulher na sociedade e resultado de políticas públicas educacionais.

Paschoal e Machado (2009) contextualizam que a educação da criança esteve sob a responsabilidade exclusiva da família durante séculos, embasada na condição de aprender as normas e regras culturais na convivência com os adultos e as outras crianças. Ferreira e Barrera (2010) salientam que a família se constitui o primeiro ambiente de socialização do indivíduo e uma das fundamentais instituições mediadoras de padrões e modelos culturais. A instituição escolar é um componente que se agregou à vida das crianças na contemporaneidade.

$\mathrm{Na}$ contemporaneidade, o desenvolvimento das instituições escolares proporcionou uma oportunidade de as crianças desenvolverem as relações sociais e constituir bases para o seu desenvolvimento em sociedade. Paschoal e Machado (2009) ressaltam que este ambiente de socialização possibilita que as crianças aprendam sobre a sua cultura por meio das interações sociais.

Alves (20II) ressalta que o surgimento de novas concepções de criança indica que a educação infantil deve ser promotora de uma aprendizagem, fundamentada na integralidade e indivisibilidade das dimensões do seu desenvolvimento. A referida autora visualiza uma intensa revisão de concepção da educação infantil em espaços coletivos, mudando do enfoque assistencial para o educacional, constituindo um processo que demanda a discussão sobre a não dissociação entre o educar e o cuidar e o estimula o desenvolvimento de questões relativas ao trabalho pedagógico nas creches e pré-escolas. Apesar desta condição, a escola não substituiu a família.

A concepção sobre a educação infantil passou por mudanças, acompanhando a modernização da sociedade em decorrência das tecnologias e, consequentemente, das mudanças culturais. Silva e Francischini (2012) relatam que a educação infantil passou 
a ocupar maiores espaços nas políticas públicas educacionais a partir do final do século $\mathrm{XX}$, evidenciando a falta de cuidado com a infância brasileira. As referidas autoras enfatizam a importância de se refletir sobre a educação infantil, pois o papel assistencialista marca as instituições de ensino públicas e o papel educacional se mantém nas instituições de ensino privadas.

Alves (2oII) aborda que o desenvolvimento e a socialização não sintetizam o papel da educação. A referida autora complementa que a educação infantil é uma etapa da educação básica e se integra ao sistema de ensino e, consequentemente, deve promover o acesso aos conhecimentos produzidos pelo homem em diversos tempos, espaços e culturas, embasando-se na contextualização, na criticidade e na adequação às faixas etárias, contribuindo para ampliação do universo cultural da criança, da compreensão da realidade e a interação com o mundo. Neste contexto de ampliação da educação infantil do país ao final do século XX, esta etapa educacional deve continuar promovendo o desenvolvimento e a socialização da criação em articulação com a promoção do conhecimento, apenas ampliando o seu alcance junto a população de crianças.

Esta reflexão é importante no desenvolvimento das políticas públicas da educação infantil, inclusive contemplando os seus três componentes. Kramer, Nunes e Corsino (20II) ressaltam que o desenvolvimento de políticas públicas de redistribuição e reconhecimento das creches se constitui fundamental, quando se apresenta uma perspectiva do atendimento aos direitos humanos e a construção de mecanismo institucionais que possibilitem o enfrentamento aos fatores socioeconômicos e culturais perpetuadores da injustiça social no país. Portanto, as políticas públicas da educação infantil devem considerar o aspecto da injustiça social que envolve a sociedade brasileira em todo o seu processo histórico.

Campos et al (20II) contemplam que as mudanças legais impulsionaram a implementação do ensino fundamental de 9 anos no país, com a inclusão do último ano da pré-escola, na condição de estratégia de apressar a universalização o atendimento educacional às crianças de 6 anos. Os referidos autores acrescentam que estratégia de política educacional implicou na redução da pré-escola de três para dois 
anos, correspondente à faixa etária de 4 e 5 anos, e ampliação da fase inicial do ensino fundamental de 4 para 5 anos.

Essas reformas educacionais proporcionam mudanças nos trabalhos administrativos das instituições de ensino e nas práticas pedagógicas. Ao analisar um sistema educacional municipal, Correa (20II) visualizou que os professores e diretores da pré-escola não foram instruídos das mudanças no ensino fundamental no ano de sua implementação, apesar de influenciar nos seus trabalhos. A referida autora complementa que as orientações da secretaria educacional se restringiram o seu enfoque na organização de matrículas, negligenciando a abordagem sobre as mudanças no desenvolvimento do trabalho pedagógico nas turmas de 3,4 e 5 anos de idade que passaram a compor as pré-escolas.

A ausência de preparação das práticas docentes para as mudanças pedagógicas não foi o único fator que foi negligenciado pelo Estado na implementação destas reformas educacionais na educação infantil e no ensino fundamental. Campos et al (20II) destacam que estas reformas educacionais foram implementadas sem a garantia de condições de infraestrutura, formação docente, redução de número de alunos por turma, adaptação de currículos e materiais didáticos, entre outras, que possibilitassem uma transição menos desarticulada para o novo formato. Os referidos autores complementam que estes percalços se desenvolvem conjuntamente aos esforços das prefeituras em atender à demanda por vagas na educação infantil, em promover a integração do atendimento que era de responsabilidade estadual e constituir a adequação de instituições conveniadas aos padrões adotados pelo setor de educação.

Neste contexto de mudanças na educação infantil, o ensino lúdico se desenvolveu por meio da implementação de novas estratégias e aprimoramento das estratégias existentes. O lúdico se demonstrou ser mais amplo do que um conjunto de brincadeiras, pois se constituiu como um conjunto amplo de estratégias de ensino para aplicação no processo de ensino-aprendizagem da educação infantil.

\section{O LÚDICO: AS ESTRATÉGIAS NA EDUCAÇÃO INFANTIL}

A estratégia do ensino lúdico encontra-se presente nas atividades que englobam a aprendizagem na educação infantil. Niles e Sosha (2014) abordam que as escolas de 
educação infantil se constituem espaços de descobertas e de ampliação das experiências individuais, culturais, sociais e educativas. As referidas autoras contemplam que a brincadeira lúdica se constitui uma estratégia que possibilita o início de adaptação da criança à realidade,

Dias (2013) salienta que as oportunidades do conhecimento oferecidas às crianças são fundamentais no desenvolvimento da sua estruturação motora, cognitiva e social. Lopes (2016) compreende que a brincadeira como prática social capacita a criança para transformar a sua realidade, por meio do desenvolvimento do imaginário e de suas habilidades. Este processo se constitui dinâmico, pois cada brincadeira produz os seus significados no processo de ensino-aprendizagem da criança.

As brincadeiras são planejadas, para serem aplicadas em conformidade com os objetivos do processo de ensino-aprendizagem. Dias (2013) destaca que estas brincadeiras demandam um trabalho da escola e do educador, pois ambos trabalham pela oferta de um espaço de alegria, de confraternização e de gosto pelo estudo, além de planejar caminhos para transformar a sociedade.

Dallabona e Mendes (2004) visualiza que a educação lúdica deve ser bem aplicada e compreendida, para proporcionar melhorias no ensino, principalmente na formação crítica, na redefinição de valores e nos relacionamentos sociais. Bonfim (20ı) visualiza que a ludicidade é importante para o desenvolvimento integral do aluno, possibilita condições para as crianças desenvolverem relações com os objetos, com o mundo e com as pessoas do seu entorno.

Nogaro, Fink e Piton (2015) observam que a relação entre o objeto e a criança é caracterizada pelos sentidos convencionais presentes na cultura da criança, e o objeto proporciona intenção e sentido à ação da criança. Os referidos autores identificam a alteração na relação entre o objeto, seu significado e sua ação, proporcionando uma condição que contribui para a criança desenvolver novas e diversas situações de interação com o objeto da brincadeira e com as outras pessoas com quem brinca, através da sua capacidade imaginação e criação.

Silva (2oII) considera que a ludicidade provém do mundo exterior e do mundo interior, pois ambos se relacionam entre si. Luckesi (2014) visualiza que a ludicidade não é igual para todos, contudo há experiências que geram um estado lúdico para 
alguns e para outros não, à medida que não pode ser medida externamente, mas somente vivenciada e expressa pelo sujeito, a partir do que é sentido na circunstância.

Pereira (2005) enfatiza que as atividades lúdicas não se restringem aos momentos divertidos ou passatempos, mas situações de descoberta, construção e compreensão de si, e envolvem também estímulos à autonomia, à criatividade, à expressão pessoal. $O$ processo de ensino-aprendizagem da educação é alinhado às brincadeiras, mas amplia-se para outras atividades, como: danças, músicas, pintura, desenho, recorte, contação de histórias e dentre outros. Nestas atividades aplicadas à educação infantil, está presente a ludicidade.

$\mathrm{Na}$ educação infantil, Silva (2016) demonstrou uma situação preocupante na educação infantil, ao constatar que a maioria dos educadores desta etapa de ensino consideram a ludicidade como jogos e brincadeiras. Estes educadores adotam uma concepção restrita da ludicidade para o processo de ensino-aprendizagem de inserção no mundo da imaginação, da criatividade, da fantasia. Destarte, negligenciam a aplicação de outras atividades como o contar histórias, o desenho, a pintura, a dramatização, a poesia, o ouvir, cantar e dançar.

Essas atividades são recorrentes nas escolas de educação infantil, realizadas no processo de ensino-aprendizagem, envolvendo objetivos e intencionalidades do educador em suas aplicações em sala de aula. Sehn (2014) ressalta que a atividade livre oportuniza o faz de conta que organiza, libera, potencializa o crescimento infantil individualmente, e em grupo, bem como as brincadeiras dirigidas pelos educadores da mesma forma contribuem para o desenvolvimento das crianças ao longo do processo de escolarização na qual elas estão inseridas. A liberdade demonstra-se como componente essencial para o desenvolvimento da criança no processo de ensinoaprendizagem.

Silva (2016) demonstra que o caráter lúdico dessas atividades no processo de ensino-aprendizagem na educação infantil configura-se como centro do mundo, pois a criança implica nas suas ações um sentido próprio, diferente da objetividade esperada pelo adulto, que é o prazer. Richter e Barbosa (20I0) enfatizam que crianças pequenas demandam interações e práticas educativas voltadas para suas experiências lúdicas e 
seus processos de aprendizagem no espaço coletivo, diferente de uma intencionalidade pedagógica voltada para resultados escolares individualizados.

Neste contexto da educação lúdica, se desenvolve a atividade de contação de histórias, como uma estratégia desenvolvida no processo de ensino-aprendizagem. A ludicidade agrega as suas características às brincadeiras na educação infantil, para promover uma aprendizagem significativa à criança, potencializando o desenvolvimento de linguagens nas crianças.

\section{AS BRINCADEIRAS NA EDUCAÇÃO INFANTIL}

As brincadeiras são componentes presentes na infância das crianças, antecedendo a entrada delas no ambiente escolar. Pereira e Pereira (2018) abordam que as brincadeiras são atividades fundamentais na educação infantil, podendo auxiliar nos seguintes aspectos: no processo de percepção e conhecimento do mundo objetivo; na interação e troca de saberes; na utilização dos conhecimentos prévios; na busca de estratégias para resoluções de problemas; nas abstrações do mundo; no desenvolvimento cognitivo, emocional e social; na aprendizagem e relacionamento de significados para aprimorar o desenvolvimento do pensamento e da linguagem. Estes aspectos se congregam no desenvolvimento global das crianças da educação infantil.

Queiroz, Maciel e Branco (2006) visualizam que as crianças são seres em desenvolvimento, com a sua brincadeira se estruturando fundamentada na sua capacidade de fazer em cada situação. As referidas autoras contemplam que as brincadeiras modificam a relação da criança com o objeto, pois este vai perdendo a sua determinação em relação à criança. As brincadeiras devem ser compreendidas no contexto das crianças, envolvendo uma dinâmica que devem possuir capacidades de mudanças nelas.

O desenvolvimento das crianças como sujeitos sociais passam pelas mudanças proporcionadas pelas atividades de brincadeiras. Silva (2020) ressalta que que o brincar é uma característica inerente ao sujeito social, produz cultura nas interações sociais e se constitui a forma de a criança vivenciar o seu contexto, explorando e conhecendo o seu entorno. Bueno (2010) visualiza a brincadeira como uma atividade social específica 
que define um vínculo com a função pedagógica da educação infantil, fundamentandose na interação e construção de conhecimentos do contexto das crianças.

A construção de conhecimentos na educação infantil corrobora a função pedagógica desta etapa da educação básica, passando pelo desenvolvimento de brincadeiras como atividades lúdicas, mediadas e direcionadas para a aprendizagem das crianças. Kishimoto (2010) indica que o ato de brincar possibilita que as crianças decidam, vivenciem a sua realidade, conheçam a si e aos outros, repitam ações prazerosas, expressem as suas identidades individuais e coletivas por meio de múltiplas linguagens, e solucionem problemas. As brincadeiras são oportunidades de agregar vivências, desenvolver relações e produzirem significados e ressignificados sobre os objetos.

Barbosa, Martins e Mello (2017) observam que as crianças desenvolvem diferentes formas de brincar, que são detentoras de coesão e sentido para elas, mas com compreensão difícil aos observadores externos. Bueno (2010) identificou a existência de valorização das atividades de brincadeiras na Educação Infantil, mas demanda-se a compreensão sobre o direcionamento destas atividades. A ausência de direcionamento torna as brincadeiras atividades de lazer e recreação, desprendendo-se da abordagem de educação lúdica.

Queiroz, Maciel e Branco (2006) salientam que a brincadeira das crianças se desenvolve principalmente nos seis primeiros anos, oportuniza a criança em construir a sua experiência de se relacionar ativamente com o mundo, por meio da tomada de decisões. De acordo com estas autoras, as crianças constroem novas e diferentes competências em seu desenvolvimento, no contexto das práticas sociais, que permitem maior compreensão do mundo. Entre as competências construídas nas brincadeiras, apresenta-se a linguagem, sendo desenvolvida em suas diversas formas nas atividades lúdicas das brincadeiras.

Moraes e Morais (2017) visualizam que o brincar é uma linguagem própria da criança, que deve ser reconhecida, pois é utilizada por ela nas situações em que possuem dificuldades de se expressar em palavras. Pinati et al (2017) compreendem que o aspecto lúdico é um fator facilitador da aprendizagem e do desenvolvimento global nas crianças. Os referidos autores indicam que as atividades lúdicas devem ser 
utilizadas amplamente como estratégia de promoção do conhecimento. A linguagem possibilita a comunicação da criança nas brincadeiras, desenvolvendo relações e interações com as outras crianças que participam da atividade.

Silva (2020) visualiza que o contato com a linguagem escrita pode ocorrer na educação infantil, independentemente das diferentes concepções pedagógicas da Educação Infantil. De acordo com a autora, a linguagem escrita pode ser articulada às brincadeiras, por meio das seguintes manifestações: brincar faz de conta; brincar de ler e escrever; e, brincar com as palavras. As brincadeiras possibilitam articular as linguagens escrita, falada e gestual, contribuindo para o desenvolvimento global das crianças da educação infantil.

Pereira e Pereira (2018) identificam que as brincadeiras ampliaram as representações mentais dos objetos do mundo real e o vocabulário, aprimorando a linguagem e o pensamento. De acordo com estas autoras, a busca pelo desenvolvimento da linguagem em uma concepção planejada deve ser um dos principais objetivos da Educação Infantil, pois a internalização dos signos e símbolos do contexto da criança e a construção de significado interferem no desenvolvimento do pensamento e da linguagem. O desenvolvimento cognitivo, motor e social passa pela construção da linguagem da brincadeira e demais linguagens constituintes se sua formação como sujeito social.

\section{CONSIDERAÇÕES FINAIS}

A educação infantil apresenta um desenvolvimento no país, nas últimas décadas. $O$ acesso das crianças às creches e pré-escolas foram ampliados, em decorrência da demanda das famílias. Essa demanda em relação à educação infantil é decorrente dose seguintes processos sociais: urbanização, crescimento econômico, lutas sociais, mudança do papel da mulher na sociedade e resultado de políticas públicas educacionais. A modernização da sociedade proporcionou novas concepções nas crianças, contribuindo para a educação infantil se constituir um instrumento de promoção de uma aprendizagem alinhada ao desenvolvimento da criança. 
Considerados estes aspectos, a educação infantil teve as suas demandas contextualizadas nas políticas públicas educacionais, em atendimento aos direitos humanos e a construção de mecanismos institucionais de enfrentamento aos problemas socioeconômicos do país. Portanto, a educação infantil se integra ao ensino fundamental e ao ensino médio, para a construção do desenvolvimento educacional do aluno na educação básica.

O ensino lúdico é constituído por estratégias direcionadas à promoção da aprendizagem na educação infantil. As brincadeiras lúdicas contribuem para adaptação da criança à realidade, proporcionando espaços de descobertas e de desenvolvimento de experiências. Além disso, elas são práticas sociais agregadoras ao desenvolvimento das estruturas motora, cognitiva e social da criança. O planejamento embasa o desenvolvimento do ensino lúdico, envolvendo o trabalho da escola e do educador, em conformidade com os objetivos do processo de ensino-aprendizagem.

No processo de ensino-aprendizagem, as estratégias lúdicas possibilitam que os alunos desenvolvam relações com os objetos, com o mundo e com as pessoas do seu entorno. Esta relação é dinâmica, pois produz significados por meio de diversas situações de interações nas brincadeiras. Ressalta-se que a ludicidade não se desenvolve igualmente em todas as crianças, sendo uma situação que deve ser considerada no planejamento do processo de ensino-aprendizagem na educação infantil. A educação lúdica é desenvolvida pelas seguintes estratégias: danças, músicas, pintura, desenho, recorte, contação de histórias e dentre outras.

O ensino lúdico demanda comprometimento do educador infantil, manifestado por meio de suas responsabilidades e compromissos. No processo de ensinoaprendizagem, a realização de intervenções adequadas demanda que o educador infantil detenha os conhecimentos sobre o universo e formação da criança. As brincadeiras apoiam as crianças em diversas ações do processo de ensinoaprendizagem da educação infantil e, consequentemente, contribuindo para o desenvolvimento global das crianças.

O desenvolvimento das crianças envolve mudanças nas relações delas com os objetos, proporcionadas pelas brincadeiras. $\mathrm{O}$ ato de brincar é inerente ao sujeito social, constituindo uma atividade específica, possibilitando a criança vivenciar o seu 
contexto e produzir cultura nas interações sociais. As brincadeiras são oportunidades de agregar vivências, desenvolver relações e produzirem significados e ressignificados sobre os objetos. Nestas atividades lúdicas, as crianças desenvolvem autonomia para tomar as decisões nas situações de brincadeiras. As ações nas brincadeiras podem não apresentar sentido para o público externo, mas elas possuem sentido para as crianças.

As brincadeiras se qualificam como uma linguagem própria das crianças na educação infantil, e contribuem para o desenvolvimento de outras linguagens. A linguagem escrita pode ser desenvolvida na educação infantil, com a utilização das brincadeiras como estratégias de ensino, articulando com as outras formas de linguagens. $O$ desenvolvimento da linguagem é planejado nas atividades de brincadeiras e mediado pelo professor de educação infantil, sendo um dos seus principais objetivos no processo de ensino-aprendizagem das crianças. A linguagem é resultante da internalização dos signos e símbolos do contexto da criança e a construção de significado.

Os resultados foram alcançados por meio da dialética entre os autores, sistematizando a construção do conhecimento que envolve este estudo. Primeiramente, compreendeu-se os aspectos da educação infantil, identificando a importância da ludicidade nas estratégias de ensino nesta etapa de formação do aluno. Aprofundou-se nas estratégias de ensino, observando os diversos recursos didáticos que se articulam com elas, para a promoção do desenvolvimento global da criança na educação infantil. Entre as estratégias de ensino lúdicas da educação infantil, identificou-se as brincadeiras. $\mathrm{Na}$ abordagem das brincadeiras identificou as suas potencialidades em relação ao desenvolvimento das linguagens nas crianças, passando pela abordagem da ludicidade que envolvem as estratégias de ensino na educação infantil.

Desta maneira, conclui-se que as brincadeiras são estratégias que facilitam o desenvolvimento das linguagens no desenvolvimento global das crianças da educação infantil. As brincadeiras se constituem como uma linguagem própria das crianças, pois são instrumentos utilizados por elas para se expressarem, em situações de dificuldades no emprego de outras linguagens na expressão. Neste contexto de desenvolvimento da linguagem, as brincadeiras devem ser desenvolvidas como atividades lúdicas 
planejadas e direcionadas para a aprendizagem das crianças no processo de ensinoaprendizagem da educação infantil.

Considerada esta abordagem, sugere-se o desenvolvimento de um estudo de abordagem sobre a produção de cultura pela criança nas brincadeiras. Esta abordagem possibilita o aprofundamento do tema sobre os potenciais das brincadeiras na educação infantil.

\section{REFERÊNCIAS BIBLIOGRÁFICAS}

ALVES, Bruna Molisani Ferreira. Infâncias e educação infantil: aspectos históricos, legais e pedagógicos. Revista Aleph, n. 16, 20II. Disponível em: 〈http://www.revistaleph.uff.br/index.php/REVISTALEPH/article/viewFile/272/ 204>. Acesso em I4 de agosto de 2021.

BARBOSA, Raquel Firmino Magalhães; MARTINS, Rodrigo Lema Del Rio; MELLO, André da Silva. Brincadeiras lúdico-agressivas: tensões e possibilidades no cotidiano na educação infantil. Movimento, v. 23, n. I, p. 159-170, 2017. Disponível em: 〈https://www.redalyc.org/pdf/II53/II53506080I2. pdf〉. Acesso em I4 de agosto de 202I.

BUENO, Elizangela. Jogos e brincadeiras na educação infantil: ensinando de forma lúdica. 2010. 42f. Trabalho de Conclusão de Curso (Licenciatura em Pedagogia), Universidade Estadual de Londrina, Londrina, 2010.

CAMPOS, Maria Malta et al. A qualidade da educação infantil: um estudo em seis capitais brasileiras. Cadernos de pesquisa, v. 4I, n. 142, p. 20-54, 2011. Disponível em: 〈http://www.scielo.br/scielo.php?pid=Soroo-1574201100oıo $003 \&$ script $=$ sci_arttext $\&$ tlng=es $>$. Acesso em I4 de agosto de 202I.

CORREA, Bianca Cristina. Políticas de educação infantil no Brasil: ensaio sobre os desafios para a concretização de um direito. Jornal de políticas educacionais, v. 5, n. 9, 
20II. Disponível em: 〈https://revistas.ufpr.br/jpe/ article/view/25172〉. Acesso em I4 de agosto de 2021.

DALlABONA, Sandra Regina; MENDES, Sueli Maria Schimit. O lúdico na educação infantil: jogar, brincar, uma forma de educar. Revista de divulgação técnicocientífica do ICPG, v. I, n. 4, p. I07-II2, 2004. Disponível em: <https:// www.inesul.edu.br/professor/arquivos_alunos/doc_1311627172.pdf>. Acesso em I4 de agosto de 2021.

DIAS, Elaine. A importância do lúdico no processo de ensino-aprendizagem na educação infantil. Revista Educação e Linguagem, v. 7, n. I, p. I-16, 2013. Disponível em: $\quad<$ http://www.ice.edu.br/TNX/storage/webdisco/2013/12/o9/outros/2774a576f5369 I7a99a29a6ec67ide86.pdf $>$. Acesso em i4 de agosto de 2021.

FERREIRA, Susie Helena Araújo; BARRERA, Sylvia Domingos. Ambiente familiar e aprendizagem escolar em alunos da educação infantil. Psico, v. 4I, n. 4, p. 12, 2010.

Disponível em: 〈https://dialnet.unirioja.es/servlet/articulo? codigo=516I409〉. Acesso em I4 de agosto de 2021.

KISHIMOTO, Tizuko Morchida. Brinquedos e brincadeiras na educação infantil. In: Seminário Nacional: Currículo em Movimento - Perspectivas Atuais, v.I, Belo Horizonte, novembro de 2010. Anais. Belo Horizonte: UFMG, 2010.

KRAMER, Sonia; NUNES, Maria Fernanda; CORSINO, Patrícia. Infância e crianças de 6 anos: desafios das transições na educação infantil e no ensino fundamental. Educaçao e Pesquisa: Revista da Faculdade de Educação da Universidade de São Paulo, v. 37, n. I, p. 69-86, 20II. Disponível em: <http:// www.scielo.br/pdf/ep/v37nI/v37niao5>. Acesso em I4 de agosto de 2021. 
LOPES, Adriana Berdeide. Luluzinhas e bolinhas na sala de aula: um estudo de gêneros na educação infantil. 2016. Trabalho de Conclusão do Curso (Especialização em Docência na Educação Infantil) - Universidade federal da Bahia, Salvador, 2016.

LUCKESI, Cipriano. Ludicidade e formação do educador. Revista Entreideias, Salvador, v. 3, n. 2, p. 13-23, jul./dez. 2014. Disponível em <https://portalseer. ufba.br/index.php/entreideias/article/view/9168/8976>. Acesso em I4 de agosto de 2021.

MORAES, João Carlos Pereira; MORAIS, Monique Godoy Gomes de. Concepções de docentes de educação física sobre a contribuição dos jogos e brincadeiras no desenvolvimento de crianças na Educação Infantil. Revista FACISA ON-LINE, v. 6, n. $\mathrm{I}, \quad 2017$ Disponível em $<\mathrm{http}: / /$ periodicos.unicathe dral.edu.br/revistafacisa/article/view/I45>. Acesso em I4 de agosto de 202I.

NILES, Rubia Paula Jacob; SOCHA, Kátia. A importância das atividades lúdicas na educação infantil. Ágora: R. Divulg. Cient, v. 19, n. I, p. 80-94, 2014. Disponível em: 〈https://pdfs.semanticscholar.org/3cb2/67b309c7aa33fe43007 b33a63d5e49fd6o4a.pdf〉. Acesso em I4 de agosto de 202I.

NOGARO, Arnaldo; FINK, Alessandra Tiburski; PITON, Marta Regina Guerra. Brincar: reflexões a partir da neurociência para a consolidação da prática lúdica na educação infantil. Revista HISTEDBR On-Line, v. 15, n. 66, p. 278-294, 2015. Disponível em: <https://periodicos.sbu.unicamp.br/ojs/index.php/histedbr/ article/view/8643715>. Acesso em I4 de agosto de 2021.

PARDAL, Maria V. de. O cuidado às crianças pequenas no Brasil escravista. In VASCONCELLOS, Vera Maria R. de. Educação da infância: história e política. Rio de Janeiro: DP\&A, 2005, p. 51-72. 
PASCHOAL, Jaqueline Delgado; MACHADO, Maria Cristina Gomes. A história da educação infantil no Brasil: avanços, retrocessos e desafios dessa modalidade educacional. Revista Histedbr on-line, v. 9, n. 33, p. 78-95, 2009. Disponível em: 〈https://periodicos.sbu.unicamp.br/ojs/index.php/histedbr/article/ view/8639555〉. Acesso em i4 de agosto de 202I.

PEREIRA, Aline Cristina Pedrozo; PEREIRA, Lilian Rodrigues Martins. Desenvolvimento da linguagem e do pensamento em jogos e brincadeiras na educação infantil. In: Colóquio Luso-Brasileiro de Educação-COLBEDUCA, v. 3, 2018. Anais. Braga e Paredes de Coura, Portugal: UDESC, 2018.

PEREIRA, Lucia Helena Pena. Bioexpressão: a caminho de uma educação lúdica para a formação de educadores. 2005. 388f. Tese (Doutorado em Educação), Faculdade de Educação, Universidade Federal da Bahia, Salvador, 2005.

PINATI, Carolina Taciana et al. Os jogos e brincadeiras na educação infantil. Ciência et Praxis, v. Io, n. I9, p. 57-62, 2017. Disponível em: <https:// revista.uemg.br/index.php/praxys/article/view/2658>. Acesso em I4 de agosto de 2021.

QUEIROZ, Norma Lucia Neris de; MACIEL, Diva Albuquerque; BRANCO, Angela Uchôa. Brincadeira e desenvolvimento infantil: um olhar sociocultural construtivista. Paidéia (Ribeirão Preto), v. 16, n. 34, p. 169-179, 2006. Disponível em: <https://www.scielo.br/scielo.php?pid=So103-863 X20060002 $00005 \&$ script $=$ sci_arttext $>$. Acesso em I4 de agosto de 202I.

RICHTER, Sandra Regina Simonis; BARBOSA, Maria Carmen Silveira. Os bebês interrogam o currículo: as múltiplas linguagens na creche. Educação, Santa Maria, v. 35 , n. I, p. 85-96, jan./abr. 2010. Disponível em <https:// periodicos.ufsm.br/reveducacao/article/view/I605>. Acesso em I4 de agosto de 202I. 
SEHN, Luize. Do cuidar ao educar na educação infantil: efeitos sentidos. 2014. 165f. Dissertação (Mestrado em Educação). Universidade Federal do Rio grande do Sul, Porto Alegre, 20I4.

SILVA, Carmem Virgínia Moraes da; FRANCISCHINI, Rosângela. O surgimento da educação infantil na história das políticas públicas para a criança no Brasil. Práxis Educacional, Vitória da Conquista v. 8, n. 12 p. 257-276 jan./jun. 2012. Disponível em: $\langle$ https://core.ac.uk/download/pdf/236649982.pdf〉. Acesso em I4 de agosto de 202I.

SILVA, Fabiana Fernandes da. A vivência lúdica na prática da Educação Infantil: dificuldades e possibilidades expressas no corpo da professora. 20II. Iogf. Dissertação (Mestrado em Educação), Universidade Federal de São João Del-Rei-Departamento de Ciências da Educação, São João Del-Rei-MG, 20 Ir.

SILVA, Isa Bastos da. O papel das brincadeiras na apropriação da linguagem escrita na educação infantil. 2020. 77 f. Trabalho de Conclusão de Curso (Licenciatura em Pedagogia), Universidade Federal da Bahia, Salvador, 2020. 